\title{
SELECTED PREGNANCY VARIABLES IN WOMEN WITH PLACENTAL ABRUPTION
}

\author{
Martin Prochazka ${ }^{\text {a*}}$, Marek Lubusky ${ }^{\mathrm{a}}$, Ludek Slavik ${ }^{\mathrm{b}}$, Petr Hrachovec ${ }^{\mathrm{a}}$, Petr Zielina ${ }^{\mathrm{a}}$, \\ Milan Kudela ${ }^{a}$, Pelle G. Lindqvist ${ }^{c}$ \\ a Department of Obstetrics and Gynecology, Faculty of Medicine and Dentistry, Palacky University, Olomouc, Czech \\ Republic \\ ${ }^{b}$ Department of Hematooncology, Faculty of Medicine and Dentistry, Palacky University, Olomouc \\ c Department of Obstetrics and Gynaecology, University Hospital MAS, Malmö, Sweden \\ e-mail: prochazka-martin@post.cz
}

Received: August 13, 2006; Accepted: October 30, 2006

Key words: Hereredity factors in thrombosis/Placental abruption/Fetal loss/Risk factors

Objective: The aim of this study was to investigate risk factors for placental abruption and to determine if anamnestic variables such as inherited thrombosis or recurrent fetal loss might be used as a predictor for placental abruption.

Methods: A retrospective case-control study at the University Hospital, Palacky University, Olomouc, Czech Republic. One hundred and eighty women with placental abruptio out of 20,175 deliveries $(0.79 \%)$ who were compared to 196 unselected pregnant women. A detailed anamnesis was taken.

Results: Compared to controls, women with placental abruptio had a 12-fold increased prevalence of prior recurrent fetal loss and a 6-fold increased prevalence of inherited thrombosis.

Conclusions: We found that recurrent fetal loss, and inherited thrombosis may be significant risk factors for placental abruptio.

\section{INTRODUCTION}

Premature separation of the placenta occurs in only $1 \%$ of all pregnancies, yet it is an important cause of stillbirth, preterm delivery, early neonatal death and even maternal death ${ }^{1}$. Placental abruptio accounts for $20 \%$ to $25 \%$ of antepartum hemorrhages. The perinatal mortality rate varies between $2 \%$ and $67 \%$, depending on gestational age, fetal weight, and the degree of abruptio. Over $50 \%$ of all perinatal deaths occur before delivery ${ }^{2}$. Placental abruptio is defined as the separation of a normally implanted placenta, usually by hemorrhage into the decidua basalis. Abruptio itself usually manifests as painful uterine bleeding and uterine irritability, sometimes in conjunction with fetal distress and maternal coagulation abnormalities.

The aim of our study was determine risk factors and to identify potential predictors of placental abruption.

\section{METHODS}

We identified 180 women out of 20,175 deliveries $(0.79 \%)$ with a confirmed diagnosis of placental abruptio at the Department of Obstetrics and Gynecology, University Hospital, Olomouc, during a 14-year period (January 1991 to July 2004). All 180 women were approached by letter to participate in the study and 142 (79\%) representing 154 babies accepted. Women participating in the study were interviewed in person and a detailed history of the situation before the index preg- nancy was made. Also, all medical records were reviewed. Gestational age was routinely estimated by ultrasound examination in mid-pregnancy. The control group was collected between January 2003 and March 2004. Every tenth woman giving birth at the delivery unit was approached to participate in the study. Two hundred and six women with uncomplicated pregnancies were approached to participate in the study. Ten women declined to participate, and thus, 196 women were included in the control group. A detailed medical history of this group was also taken before delivery as part of the clinic routine and their medical records were reviewed. The Ethics Committee of the Medical Faculty of Palacký University approved the study design, and informed consent was obtained from all participants.

\section{Characteristics}

The mean age for study group and the control group was 27.5 years $( \pm 5.4)$ and 28.8 years $( \pm 5.1)$. The neonates from the study group were at a significantly lower gestational age and had a lower birth weight than the control group (33.5 \pm 4.8 and $39.1 \pm 2.0$ weeks) and $2164 \mathrm{~g} \pm 984$ and $3385 \mathrm{~g} \pm 539$. The $\mathrm{pH}$ of the umbilical artery was not statistically different between the two groups $(7.30 \pm 0.14$ $[\mathrm{n}=106]$ and $7.32 \pm 0.06[\mathrm{n}=103]$ cases, $p<0.18)$.

The diagnosis of placental abruptio was based on clinical examination. Women usually presenting with a combination of profuse vaginal bleeding and painful contractions. All placentas were examined macroscopically. Recurrent pregnancy loss was defined as three or more first trimester losses, one second trimester fetal loss with 
Table 1. Characteristics of women with placental abruption and controls.

\begin{tabular}{|l|c|r|r|r|r|rr|}
\hline \multicolumn{1}{|c|}{$\begin{array}{c}\text { Established risk factors } \\
\text { for placental abruption }\end{array}$} & \multicolumn{2}{c|}{$\begin{array}{c}\text { Placental abruption } \\
(\mathrm{n}=142)\end{array}$} & \multicolumn{2}{c|}{$\begin{array}{c}\text { Control group } \\
(\mathrm{n}=196)\end{array}$} & \multicolumn{2}{c|}{$\mathrm{p}$} & \multicolumn{2}{c|}{ OR (95\% CI) } \\
\hline Smokers & 38 & $26.8 \%$ & 25 & $12.7 \%$ & 0.0011 & 2.5 & $(1.4-4.6)$ \\
\hline Intrauterine growth restriction & 14 & $9.8 \%$ & 7 & $3.6 \%$ & 0.0180 & 3.0 & $(1.1-8.3)$ \\
\hline Preclampsia & 10 & $7.0 \%$ & 2 & $1.0 \%$ & 0.0031 & 7.4 & $(1.5-49.4)$ \\
\hline Chronic hypertension & 5 & $3.5 \%$ & 4 & $2.0 \%$ & 0.4040 & 1.8 & $(0.4-7.9)$ \\
\hline Premature rupture of membranes & 37 & $25.3 \%$ & 10 & $5.1 \%$ & 0.0000 & 6.6 & $(3.0-14.7)$ \\
\hline Chorionamnionitis & 10 & $7.0 \%$ & 2 & $1.0 \%$ & 0.0031 & 7.4 & $(1.5-49.4)$ \\
\hline Male fetal gender & 78 & $55.9 \%$ & 95 & $48.5 \%$ & 0.2409 & 1.3 & $(0.8-2.1)$ \\
\hline Recurrent fetal loss & 23 & $16.2 \%$ & 3 & $2.0 \%$ & 0.0000 & 12.4 & $(3.5-53.2)$ \\
\hline Thrombosis heredity & 24 & $16.2 \%$ & 6 & $3.1 \%$ & 0.0000 & 6.4 & $(2.4-18.2)$ \\
\hline
\end{tabular}

Numbers, percentage, p-value and odds ratios (OR) with its $95 \%$ confidence intervals (CI) are given.

subsequent one or more consecutive first trimester fetal loss(es), or at least two second trimester losses.

Stillbirth, defined as intrauterine death after 24 weeks of gestation, occurred in 4 cases $(2.8 \%)$ in the placental abruptio group. Smoking habits and first degree heritage of thrombosis in the control group were recorded at the last antenatal visit. The data in the study group were based on the detailed history-taking and retrospective review of the medical records. Gestational age was estimated by sonographic measurement at the end of the first trimester. Small for gestational age was defined as a newborn whose birthweight was below the $5^{\text {th }}$ percentile. Preterm delivery was defined as delivery before 37 weeks of gestation.

Diagnosis of chorioamnionitis was based on the histopathological examination of the placenta and a combination of clinical signs (fever, pain, fetal distress) and elevated inflammation markers (white blood cell count, CRP).

Premature rupture of the membranes (PROM) was defined as rupture of membranes more than 24 hours before delivery. The diagnosis of PROM was based on clinical signs (amniotic fluid index measured by ultrasound and detection of amniotic fluid microscopically and chemically).

Pre-eclampsia was defined as hypertension in pregnancy $(>140 / 90)$ and proteinuria (>300 mg/l). Pregnancyinduced hypertension was defined as hypertension in pregnancy measured on two occasions at an interval of at least five hours, and having developed after 20 weeks of gestation in a previously normotensive pregnancy.

\section{Statistics}

The $\chi^{2}$ test or Fischer's exact test was used for analysis of categorical variables. All calculations were performed by Statsoft, Inc. (2001) Statistika Cz (software system data analysis), version $6, \mathrm{p}<0.05$ was considered statistically significant.

\section{RESULTS}

Characteristics of pregnancies with placental abruptio and controls that might effect the risk of placental abruptio are given in Table 1. As expected, the prevalence of established risk factors such as maternal smoking, intrauterine growth restriction, preeclampsia, chorionamnionitis, and PROM were significantly greater in the study group compared to the control group ${ }^{1}$.

Of the 23 women with recurrent fetal loss in the placental abruption group, 18 had three or more first trimester fetal losses, and 5 had at least two second trimester fetal losses. Of the 3 cases of recurrent fetal loss in the control group, all three were only first trimester fetal losses. We found both prior recurrent pregnancy loss and inherited thrombosis to be significant risk factors for placental abruption (Table 1).

\section{DISCUSSION}

In this retrospective case-control study we found prior recurrent fetal loss, first degree heritage of thrombosis to be significant risk factors for developing placental abruption. We were able to confirm the recent finding that first degree thrombosis heredity was a risk factor for placental abruptio $^{3}$. In addition, our data support the established risk factors relation to placental abruptio. Also, the predominance of male fetal gender is in agreement with Kramer and coworkers ${ }^{1}$.

Our results might be of value in both etiological research of placental abruptio and for the clinical management of women with premature contractions or late hemorrhage during pregnancy. These women might, in the presence of risk factor(s), need more intense surveillance. Both first degree heredity of thrombosis and the presence of prior recurrent fetal loss are easily assessable 
by anamnesis and laboratory investigation of coagulation parameters is often performed in relation to both heredity of thrombosis and recurrent fetal loss. The exact etiological background to placental abruptio is still unknown. More research is needed to establish the exact relation of placental abruptio to maternal thrombophilia with special reference to combined thrombophilias. Also, there is lack of information of the interaction between maternal and fetal genotypes. We found prior recurrent fetal loss and first degree thrombosis heredity to be significant risk factors for placental abruptio and there might be used for predictive purposes.

\section{ACKNOWLEDGMENTS}

The study was supported by the grant of the Ministery of Health of The Czech Republic IGA MZd. NH/6986-3, 2002. We would also like to thanks to Dr. M. Krskova (Department of Biostatistics) for the stimulating discussion and statistical analysis.

\section{REFERENCES}

1. Kramer MS, Usher RH, Pollack R, Boyd M, Usher S. Etiologic determinants of abruptio placentae. Obstet Gynecol 1997; 89:2216.

2. James DK, Steer P, Weiner C, Gonic B. High risk pragnancy, Management options. London Saunders, 1995.

3. Procházka M, Happach C, Marsal K, Dahlbäck B, Lindqvist PG. Factor $\mathrm{V}$ Leiden in pregnancies complicated by placental abruption. Br J Obstet Gynaecol 2003; 110:462-466. 